\title{
Prenatal and Early Life Exposure to Traffic Pollution and Cardiometabolic Health in Childhood
}

Abby F. Fleisch ${ }^{1}$, Heike Luttmann-Gibson ${ }^{2}$, Wei Perng ${ }^{3}$, Sheryl L. Rifas-Shiman ${ }^{4}$, Brent A. Coull $^{5}$, Itai Kloog ${ }^{6}$, Petros Koutrakis ${ }^{2}$, Joel D. Schwartz ${ }^{2}$, Antonella Zanobetti ${ }^{2}$, Christos S. Mantzoros ${ }^{7}$, Matthew W. Gillman ${ }^{4,8}$, Diane R. Gold ${ }^{2,9}$, Emily Oken ${ }^{4,8}$

\author{
Affliliations \\ ${ }^{1}$ Division of Endocrinology, Boston Children's Hospital, Boston, MA, USA \\ ${ }^{2}$ Department of Environmental Health, Harvard TH Chan School of Public Health, Boston, MA, \\ USA \\ ${ }^{3}$ Department of Nutritional Sciences, Department of Epidemiology, University of Michigan \\ School of Public Health, Ann Arbor, MI, USA \\ ${ }^{4}$ Obesity Prevention Program, Department of Population Medicine, Harvard Medical School and \\ Harvard Pilgrim Health Care Institute, Boston, MA, USA \\ ${ }^{5}$ Department of Biostatistics, Harvard TH Chan School of Public Health, Boston, MA, USA \\ ${ }^{6}$ Department of Geography and Environmental Development, Ben-Gurion University of the \\ Negev, Beer Sheva, Israel \\ ${ }^{7}$ Division of Endocrinology, Diabetes, and Metabolism, Department of Medicine, Beth Israel \\ Deaconess Medical Center, Harvard Medical School, Boston, MA, USA \\ ${ }^{8}$ Department of Nutrition, Harvard TH Chan School of Public Health, Boston, MA, USA \\ This is the author manuscript accepted for publication and has undergone full peer review but has \\ not been through the copyediting, typesetting, pagination and proofreading process, which may \\ lead to differences between this version and the Version of Record. Please cite this article as doi: \\ 10.1111/ijpo.12106
}

This article is protected by copyright. All rights reserved. 
${ }^{9}$ Channing Laboratory, Brigham and Women's Hospital, Boston, MA, USA

\section{Corresponding author:}

Abby F. Fleisch, MD, MPH

Department of Endocrinology

Boston Children's Hospital

300 Longwood Ave

Boston, MA 02115

abby.fleisch@childrens.harvard.edu

Phone: 617-355-7476, FAX: 617-730-0194

Running title: Traffic Pollution and Childhood Cardiometabolic Health

Key words: Adiposity, air pollution, cardiometabolic health, $\mathrm{PM}_{2.5}$, pregnancy, traffic

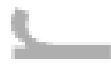

Abbreviations: BC, black carbon; BMI, body mass index; CI, confidence interval; HOMA-IR, homeostasis model assessment for insulin resistance; LMP, last menstrual period; $\mathrm{PM}_{2.5}$, fine particulate matter; RAs, research assistants; SD, standard deviation; SES, socioeconomic status; SS, subscapular; TR, triceps; UFP, ultrafine particles 


\section{ABSTRACT}

Background: Prenatal exposure to traffic pollution has been associated with faster infant weight gain, but implications for cardiometabolic health in later childhood are unknown.

Methods: Among 1,418 children in Project Viva, a Boston-area pre-birth cohort, we assessed anthropometric and biochemical parameters of cardiometabolic health in early (median age 3.3

years) and mid- (median age 7.7 years) childhood. We used spatiotemporal models to estimate prenatal and early life residential $\mathrm{PM}_{2.5}$ and black carbon exposure as well as traffic density and roadway proximity. We performed linear regression analyses adjusted for sociodemographics Results: Children whose mothers lived close to a major roadway at the time of delivery had higher markers of adverse cardiometabolic risk in early and mid-childhood. For example, total fat mass was $2.1 \mathrm{~kg}(95 \% \mathrm{CI}: 0.8,3.5)$ higher in mid-childhood for children of mothers who lived $<50 \mathrm{~m}$ vs. $\geq 200 \mathrm{~m}$ from a major roadway. Black carbon exposure and traffic density were generally not associated with cardiometabolic parameters, and $\mathrm{PM}_{2.5}$ exposure during the year prior was paradoxically associated with improved cardiometabolic profile

Conclusions: Infants whose mothers lived close to a major roadway at the time of delivery may be at later risk for adverse cardiometabolic health. 


\section{INTRODUCTION}

Childhood obesity is epidemic, recalcitrant to treatment, and associated with costly comorbidities, including adverse cardiometabolic health that tracks into adulthood. ${ }^{1}$ The prenatal and early life environment influences propensity for excess adiposity, ${ }^{2}$ and it is a priority to identify remediable early life environmental triggers.

= Air pollution is one environmental exposure that may promote adiposity. After release from automobiles and power plants, gaseous and particulate air pollutants with an aerodynamic diameter less than $2.5 \mu \mathrm{m}\left(\mathrm{PM}_{2.5}\right)$ enter the airways and may induce adiposity and dysmetabolism through endothelial dysfunction, inflammation, and oxidative stress. ${ }^{3}$ In rodents, $\mathrm{PM}_{2.5}$ exposure altered adipokine secretion and increased adipose inflammation, visceral adiposity, and insulin resistance. ${ }^{4,5}$

Despite a convincing rodent literature, there has been limited investigation of $\mathrm{PM}_{2.5}$ on cardiometabolic health in human studies. Prior cohorts have demonstrated an association between air pollution exposure and obesity in childhood ${ }^{6-9}$ but included limited investigation of adipose distribution and no consideration of cardiometabolic biomarkers. Population-based studies in children ${ }^{10-12}$ and adults ${ }^{13}$ have linked air pollution exposure with insulin resistance but lacked consideration of prenatal exposures despite emerging evidence that in utero air pollution exposure may prime offspring for adiposity. ${ }^{8,14}$ Late prenatal exposure to traffic pollution was associated with faster infant weight gain in our prior analysis of the Boston-area Project Viva cohort, ${ }^{14}$ but whether these weight-promoting effects persist throughout childhood and whether exposure is also associated with adverse cardiometabolic health in childhood is unclear. 
In the present analysis, our primary objective was to evaluate the extent to which late prenatal exposure to $\mathrm{PM}_{2.5}$ and black carbon (BC) (a traffic-related $\mathrm{PM}_{2.5}$ component), as well as residential traffic density and roadway proximity, were associated with anthropometric and biochemical markers of adiposity and insulin resistance in early and mid-childhood. We also evaluated postnatal, proximate pollution exposures. We hypothesized that air pollution exposure would be associated with an adverse cardiometabolic profile.

\section{METHODS}

\section{Study population and design}

Participants were recruited to Project Viva, a prospective cohort study of prenatal exposures and offspring health, from 1999 to 2002 during their first prenatal visit to Atrius Health in eastern Massachusetts. ${ }^{15}$ Of 2,128 participants with a live singleton offspring, 1,418 had data for at least one exposure and one outcome studied. We included a subset in each analysis based primarily on available outcome data (Figure S1). As compared to those without follow-up, mothers of children who attended early and mid-childhood visits were more likely to be nonsmokers, college graduates, and have higher birth weight-for-gestational age infants

\section{(Table S1).}

Mothers provided informed consent at enrollment and for their child at each in-person visit. Institutional Review Boards of participating institutions approved the study.

\section{Air pollution exposures}

This article is protected by copyright. All rights reserved. 
Participants provided their residential address at enrollment (median 9.9 weeks gestation) and updated it at study visits at the end of the second trimester, soon after birth, and during their child's infancy (median: 6 months of age), early childhood (median: 3.3 years of age), and midchildhood (median: 7.7 years of age). Our estimates of residential $\mathrm{BC}$ and $\mathrm{PM}_{2.5}$ exposure accounted for moves during exposure windows of interest.

We estimated daily BC exposure with a land-use regression model (mean "out-ofsample" ten-fold cross-validation $\left.\mathrm{R}^{2}=0.73\right) .{ }^{16}$ We used aerosol optical depth data to estimate $\mathrm{PM}_{2.5}$ exposure at 10x10 km spatial grid resolution (mean daily "out-of-sample" ten-fold crossvalidation $\mathrm{R}^{2}=0.87$ for days with aerosol optical depth data and 0.85 for days without). ${ }^{17}$ To obtain third trimester exposure estimates, we averaged daily exposures from the $188^{\text {th }}$ day (i.e.27 weeks gestation) after the last menstrual period (LMP) to the day before birth. To obtain exposure estimates for the year prior to the health outcome measurement, we averaged daily exposures over 365 days prior to the in-person visit (anthropometric outcomes) or blood draw (biomarker outcomes). We assigned exposures to addresses where model predictions were available (Eastern Massachusetts for the BC model and New England for the $\mathrm{PM}_{2.5}$ model) for at least $90 \%$ of days in an exposure period. We also examined associations using our model for $\mathrm{PM}_{2.5}$ exposure at $1 \times 1 \mathrm{~km}$ spatial grid resolution, ${ }^{18}$ available after 2003 . Results using this model were similar, and because estimates were not available for prenatal time periods, we present all results using the $10 \times 10 \mathrm{~km} \mathrm{PM}_{2.5}$ model.

We used the 2002 road inventory from the Massachusetts Executive Office of Transportation to calculate traffic density by multiplying annual average daily traffic 
(vehicles/day) by length of road $(\mathrm{km})$ within $100 \mathrm{~m}$ of participants' residential address. We used 2005 ESRI Street Map ${ }^{\text {TM }}$ North America ArcGIS 10 Data and Maps to estimate home roadway proximity as distance to Census Feature Class Code A1 or A2 roads (i.e.- -highways).

\section{Assessment of child anthropometry and cardiometabolic biomarkers}

" Research assistants (RAs) measured participants' weight in light clothing using an electronic scale (Tanita, Arlington Heights, IL) and height without shoes using a stadiometer (Shorr Productions, Olney, MD). We calculated age- and sex-specific BMI z-scores from CDC 2000 reference data. RAs used Holtain calipers (Cross-well, UK) to measure subscapular (SS) and triceps (TR) skinfold thicknesses, and we calculated the sum (SS + TR) of the skinfold thicknesses. RAs measured waist circumference underneath clothing using a nonstretchable measuring tape (Hoechstmass Balzer GmbH, Sulzbach, Germany). We measured total and truncal fat mass using a Hologic DXA scan (Bedford, MA).

In early and mid-childhood, we measured plasma leptin and adiponectin concentrations, and in mid-childhood, plasma fasting glucose and insulin, as previously described. ${ }^{19} \mathrm{We}$ calculated the homeostasis model assessment for insulin resistance (HOMA-IR) [glucose (mg/dL) $\mathrm{x}$ insulin $(\mathrm{mU} / \mathrm{L})) / 405]$.

\section{Covariates}

We obtained mothers' age, race/ethnicity, education, and smoking habits at study enrollment. We calculated pre-pregnancy BMI from self-reported weight and height. Women 
underwent a two-tiered glucose screening test during pregnancy, as previously described. ${ }^{20} \mathrm{We}$ obtained infant sex, birth weight, and date of delivery from the hospital medical record. We calculated length of gestation by LMP and birth weight-for-gestational age and sex z-score from a US national reference. ${ }^{21}$ We abstracted residential census tract median annual household income at the time of delivery from 2000 US Census data.

\section{Statistical analyses}

We used linear regression to evaluate associations of air pollution exposures with anthropometric and cardiometabolic biomarkers in early childhood (BMI z-score, waist circumference, sum of skinfold thickness, leptin, and adiponectin) and mid-childhood (BMI zscore, total fat mass, truncal fat mass, leptin, adiponectin, and HOMA-IR). For outcomes available at both time points, we examined each separately to accommodate potential differences in the association between the outcome and each confounder by developmental stage. Blood concentrations of leptin, adiponectin, and HOMA-IR were not normally distributed so we lntransformed them for analyses. For ease of interpretation we exponentiated resulting regression coefficients, which we report as a percent change.

We considered each exposure (BC, $\mathrm{PM}_{2.5}$, traffic density, and roadway proximity) at each time period in separate models. To account for the exponential spatial decay of traffic pollution, ${ }^{22}$ we a priori categorized residential proximity to major roadway as $\geq 200 \mathrm{~m}, 100$ to $<200 \mathrm{~m}, 50$ to $<100 \mathrm{~m}$, and $<50 \mathrm{~m}$, as we have done previously. ${ }^{14}$ We initially modeled $\mathrm{BC}, \mathrm{PM}_{2.5}$,

and traffic density in quartiles, and because exposure-outcome relationships appeared linear, we 
reported continuous measures and expressed associations per interquartile range (IQR)

increment.

We first fit unadjusted models, followed by full multivariable models for each exposure-outcome relationship. We included covariates potentially associated with air pollution exposure and/or childhood cardiometabolic health: maternal age (continuous), education (with or without college degree), and smoking habits (smoked during pregnancy, formerly smoked, never smoked); child age (continuous), sex (dichotomous), and race/ethnicity (white, black, Asian, Hispanic, other); and census tract median household income (continuous). To account for trends in air pollution and adiposity by season and over time, we also included season (continuous sine and cosine of date) and date (continuous) at the time of health outcome in multivariable models. We did not include personal household income, fetal growth, or maternal glucose tolerance because inclusion did not appreciably change results. We substituted maternal for child race/ethnicity in $10 \%$ of participants missing data on child race/ethnicity. $98 \%$ of participants had complete covariate information for the multivariable models. We found no effect modification by child sex or maternal pre-pregnancy BMI, so we present all results without stratification or inclusion of an interaction term for these variables.

In secondary analyses, we examined associations of $\mathrm{BC}$ and $\mathrm{PM}_{2.5}$ exposure during other time periods $\left[\right.$ i.e. first trimester (date of LMP to $93^{\text {rd }}$ day after LMP), second trimester $\left(94^{\text {th }}\right.$ day after LMP to $187^{\text {th }}$ day after LMP), and one week prior to health outcome assessment] with early and mid-childhood cardiometabolic health. To account for potential bias due to cohort attrition, we repeated key analyses of roadway proximity at delivery and cardiometabolic outcomes using 
inverse probability weighting. In addition, because roadway category sample sizes were small (Table S3) and because we occasionally identified non-monotonic associations (Tables 2 and 3), we also performed a penalized spline analysis using R Version 3.0.0 (R Foundation for Statistical Computing, Vienna, Austria) to evaluate potential non-linearity across the range of roadway proximity. For all other analyses, we used SAS version 9.3 (SAS Institute, Cary NC).

$$
=
$$

(

\section{RESULTS}

\section{Population characteristics}

Mean(SD) maternal age was 32.1(5.2) years; $68 \%$ of mothers were college graduates, and $69 \%$ were non-smokers. $64 \%$ of children were white. Details on early and mid-childhood cardiometabolic outcomes are presented in Table 1.

Third trimester mean(SD, range) BC concentration was $0.7 \mu \mathrm{g} / \mathrm{m}^{3}(0.2,0.1-1.6)$. For context, the annual US urban average ranged $0.2-1.9 \mu \mathrm{g} / \mathrm{m}^{3}$ from $2005-2007 .^{23}$ Third trimester mean(SD, range) $\mathrm{PM}_{2.5}$ concentration was $11.8 \mu \mathrm{g} / \mathrm{m}^{3}(1.6,7.5-16.8)$, and the Environmental Protection Agency air quality standard for annual $\mathrm{PM}_{2.5}$ exposure was $15 \mu \mathrm{g} / \mathrm{m}^{3}$ during 1999 2002. At the time of delivery, mean(SD, range) neighborhood traffic density was $1,410(1,846,0$ $30,860)$ vehicles/day $\mathrm{x} \mathrm{km}$ of road within $100 \mathrm{~m}$ of residential address; most mothers (88\%) lived $\geq 200 \mathrm{~m}$ from a major roadway, and $3 \%$ lived $<50 \mathrm{~m}$. Exposures were moderately correlated (Spearman correlation coefficients 0.10-0.64) (Table S2).

Mothers with lower $3^{\text {rd }}$ trimester BC exposure were more likely to be older, educated, nonsmokers, and live in a census tract with higher median household income. Their children 
were more likely to be white, heavier at birth, and younger at follow-up visits with lower leptin concentration in early childhood and lower total and truncal fat mass, leptin, and HOMA-IR in mid-childhood (Table 1).

\section{Air pollution exposure and early childhood cardiometabolic risk}

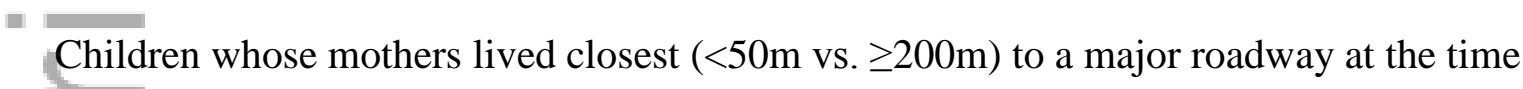
of delivery had $0.3 \mathrm{~kg} / \mathrm{m}^{2}$ (95\%CI: $\left.0.0,0.7\right)$ higher BMI, $1.7 \mathrm{~cm}$ (95\%CI: $\left.0.6,2.8\right)$ larger waist circumference, $1.9 \mathrm{~mm}$ (95\%CI: 0.6, 3.2) larger sum of skinfold thickness, and 40.7\% (95\%CI: $5.2,88,1)$ higher leptin concentration in early childhood. Children whose mothers lived intermediate distances from a major roadway at delivery $(100-<200 \mathrm{~m})$ also had higher BMI zscore and larger waist circumference in early childhood. Residential roadway proximity in early childhood was contemporaneously associated with increased leptin concentration but not other cardiometabolic outcomes (Table 2).

For each IQR increment in neighborhood traffic density at the time of delivery, early childhood leptin concentration was $5.4 \%$ (95\%CI: $1.3,9.7)$ higher. Traffic density was not associated with other early childhood cardiometabolic parameters. Prenatal and contemporaneous $\mathrm{BC}$ and $\mathrm{PM}_{2.5}$ exposure were not associated with cardiometabolic risk in early childhood (Table 2).

\section{Air pollution exposure and mid-childhood cardiometabolic risk}


Children whose mothers lived closest $(<50 \mathrm{~m}$ vs. $\geq 200 \mathrm{~m})$ to a major roadway at the time of delivery had $2.1 \mathrm{~kg}(95 \% \mathrm{CI}: 0.8,3.5)$ greater total fat mass, $0.9 \mathrm{~kg}(95 \% \mathrm{CI}: 0.4,1.5)$ greater truncal fat mass, and 78.3\% (95\%CI: 18.5, 168.3) higher leptin concentration in mid-childhood. Children whose mothers lived intermediate distances from a major roadway at delivery (100$<200 \mathrm{~m}$ ) had higher BMI z-score and higher total and truncal fat mass in mid-childhood. $=$ Residential roadway proximity at the time of the mid-childhood follow-up visit was not associated with cardiometabolic outcomes (Table 3).

In contrast to our a priori hypothesis, exposure to $\mathrm{PM}_{2.5}$ during the year prior to the midchildhood visit was associated with lower rather than higher BMI z-score, total and truncal fat mass, and HOMA-IR [e.g. truncal fat mass was $0.3 \mathrm{~kg}(95 \% \mathrm{CI}$ : -0.5, -0.0) lower for each IQR increment $\mathrm{PM}_{2.5}$ ]. Also, for each IQR increment in neighborhood traffic density at the time of delivery, mid-childhood HOMA-IR was 5.7\% (95\%CI: -10.1, -1.1) lower. Other air pollution exposure metrics were not associated with mid-childhood outcomes (Table 3).

\section{Secondary analyses}

When we considered associations of $\mathrm{BC}$ and $\mathrm{PM}_{2.5}$ exposure during first and second trimesters and one week prior to the health outcome assessment, for each IQR increment in $\mathrm{PM}_{2.5}$ exposure during the first trimester, adiponectin in early childhood was 5.8\% lower (95\%CI: $10.5,-1.0)$. Contrary to our a priori hypothesis, for each IQR increment in BC exposure during the week prior, HOMA-IR was $17.1 \%$ lower (95\%CI: -27.6, -5.2) in mid-childhood, not higher. Other exposure-outcome relationships were null (data not shown). 
In analyses with (versus without) inverse probability weighting, roadway proximity at delivery had stronger associations with early childhood outcomes and similar associations with mid-childhood outcomes (Table S4). In the penalized spline model, roadway proximity at delivery and mid-childhood truncal fat mass showed a stronger association with closer roadway proximity(Figure 2) with similar results for total fat mass (data not shown).

\section{DISCUSSION}

In our analysis of a large prospective cohort, infants whose mothers lived close to a major roadway at the time of delivery had greater adiposity in early and mid-childhood. However, prenatal and early life exposure to air pollutants and traffic density were not consistently associated with adiposity or insulin resistance.

Our findings suggest that features of roadway proximity distinct from air pollution (or from the pollutants we measured) may contribute to later cardiometabolic risk. For example, sleep disruption from roadway noise ${ }^{24}$ and light, ${ }^{25}$ as well as reduced neighborhood walkability ${ }^{26}$ are roadway characteristics independently associated with adiposity and dysmetabolism. Alternatively, ultrafine particles (UFPs), which were not measured in our cohort, could have driven the association between residential roadway proximity and cardiometabolic health. UFPs, which have a diameter $<0.1 \mu \mathrm{m}$ and are primarily emitted from vehicle exhaust, have been increasingly implicated in health effects, particularly in urban areas. UFPs increase with vehicle speed and decrease with idling, features common to traffic on major roadways, and they aggregate quickly to form larger particles, so concentrations fall rapidly with distance from 
roadway. ${ }^{27}$ Our findings may be impacted by unmeasured confounding by socioeconomic status (SES), although roadway proximity was not as tightly correlated as air pollution with the SES factors measured in our cohort (data not shown). The findings may also reflect random chance, particularly given the small sample sizes in the roadway categories. However, an inverse association between roadway proximity and childhood adiposity in spline models suggests against this possibility.

Our results are consistent with one prior study in which residential roadway proximity $(<50 \mathrm{~m})$ but not $\mathrm{PM}_{2.5}$ predicted incident type 2 diabetes mellitus in adult women. ${ }^{28}$ Also, in the Project Viva cohort, impaired neurocognition in childhood was similarly associated with roadway proximity $(<50 \mathrm{~m})$ at the time of delivery but not at the time of cognitive testing, ${ }^{29}$ raising the possibility of an in utero programming effect. Nevertheless, our findings require replication in other populations of pregnant women and children.

We did not observe consistent associations of $\mathrm{BC}, \mathrm{PM}_{2.5}$, or traffic density exposures with childhood cardiometabolic parameters, although there were a few sporadic associations that did not follow a clear pattern. For example, neighborhood traffic density at the time of delivery and contemporaneous roadway proximity were associated with higher leptin in early childhood. Also, contrary to our a priori hypothesis, $\mathrm{PM}_{2.5}$ exposure during the year prior was associated with lower rather than higher BMI z-score, total and truncal fat mass, and HOMA-IR. Although the $\mathrm{PM}_{2.5}$ model estimated $10 \times 10 \mathrm{~km}$ exposures which could limit local contrast and bias results toward the null, it is unlikely to have led to negative associations. The negative associations are somewhat consistent with one rodent study in which overweight but not normal 
weight mice exposed to $\mathrm{PM}_{2.5}$ in early childhood had non-significantly lower HOMA-IR and body weight, ${ }^{5}$ and this is in line with an above average BMI z-score of children in our cohort. However, this finding has not been replicated in other animal or human studies, and the biological basis is not clear.

The bulk of the existing rodent and human literature supports an association between air $=$

pollutants and cardiometabolic health. In rodents, air pollution exposure led to visceral adiposity and insulin resistance with effects mediated through induction of oxidative stress and systemic inflammation, ${ }^{4,5}$ as well as neuroinflammation with consequent brain remodeling and altered satiety signals. ${ }^{30}$ In cohort studies of prenatal exposure, polycyclic aromatic hydrocarbon (a combustion byproduct of fossil fuel and biomass burning $)^{8}$ has been associated with early childhood obesity, and Project Viva infants born to mothers living in neighborhoods with higher traffic density had more rapid weight gain and greater risk of weight-for-length $>95^{\text {th }}$ percentile by 6 months of age. ${ }^{14}$ In elementary ${ }^{9}$ and teenage ${ }^{6}$ cohorts in Southern California, residential traffic pollution (NOx) at enrollment was associated with BMI over 4-8 years of follow-up, and elementary school children in China were more likely to be obese if school/residential air pollution $\left(\mathrm{PM}_{10}, \mathrm{SO}_{2}\right.$, and $\left.\mathrm{O}_{3}\right)$ was higher during the two years preceding the weight measurement. ${ }^{7}$ Additionally, population-based studies in $\operatorname{Iran}{ }^{10,12}$ and Germany ${ }^{11}$ have demonstrated an association between air pollution exposure and insulin resistance in childhood. Limitations of Project Viva that may have prevented us from observing a persistent association between early life air pollution exposure and cardiometabolic outcomes include generally low air pollution exposures in the Boston area and a cohort of primarily white children 
of moderately high SES at relatively low risk for adverse cardiometabolic health. Strengths of included use of a large, prospective cohort with multiple potential confounding variables, several measures of air pollution exposure with daily spatiotemporal resolution, and evaluation of both anthropometric and serum markers of dysmetabolism at two time points in childhood.

In conclusion, infants whose mothers lived close to a major roadway at the time of delivery were at risk for adverse cardiometabolic parameters in early and mid-childhood. However, we found no evidence of a persistent effect of prenatal or early life BC or $\mathrm{PM}_{2.5}$ exposures on childhood cardiometabolic profile in a population with relatively high SES exposed to modest levels of air pollution.

\section{CONFLICTS OF INTEREST STATEMENT}

The authors declare no conflict of interest.

\section{AUTHOR CONTRIBUTIONS}

AFF conceived this analysis and drafted the manuscript. AFF, HL-G, WP, and SLR-S performed the analysis. All authors critically reviewed the manuscript.

\section{ACKNOWLEDGEMENTS}


We thank Maria Harris for helpful discussions about refining exposure measures. We also appreciate the work of past and present Project Viva staff and the ongoing participation of the Project Viva mothers and children.

The authors have received support from the National Institutes of Health (K24HD069408, R37HD034568, P30DK092924, P30ES000002, P01ES009825, R01AI102960, K12DK094721, K23ES024803), the Environmental Protection Agency (RD83479801), the Harvard School of Public Health, and the Harvard Pilgrim Health Care Institute. This publication's contents are solely the responsibility of the grantee and do not necessarily represent the official views of the US EPA or any other organization. Further, US EPA does not endorse the purchase of any commercial products or services mentioned in the publication.

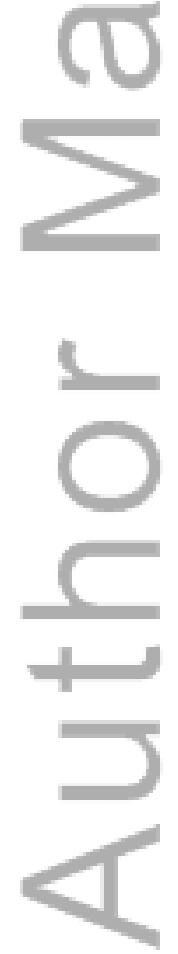




\section{REFERENCES}

1. Singh AS, Mulder C, Twisk JW, van Mechelen W, Chinapaw MJ. Tracking of childhood overweight into adulthood: a systematic review of the literature. Obes Rev. Sep 2008;9(5):474-488.

2. Symonds ME, Sebert SP, Hyatt MA, Budge H. Nutritional programming of the metabolic syndrome. Nat Rev Endocrinol. Nov 2009;5(11):604-610.

3. McConnell R, Gilliland FD, Goran M, Allayee H, Hricko A, Mittelman S. Does nearroadway air pollution contribute to childhood obesity? Pediatr Obes. Mar 272015.

4. = Sun Q, Yue P, Deiuliis JA, et al. Ambient air pollution exaggerates adipose inflammation and insulin resistance in a mouse model of diet-induced obesity. Circulation. Feb 3 2009;119(4):538-546.

5. Xu X, Yavar Z, Verdin M, et al. Effect of early particulate air pollution exposure on obesity in mice: role of p47phox. Arterioscler Thromb Vasc Biol. Dec 2010;30(12):25182527.

6. McConnell R, Shen E, Gilliland FD, et al. A longitudinal cohort study of body mass index and childhood exposure to secondhand tobacco smoke and air pollution: the Southern California Children's Health Study. Environ Health Perspect. Apr 2015;123(4):360-366.

7. Dong G, Qian Z, Liu M, et al. Ambient Air Pollution and the Prevalence of Obesity in Chinese Children: The Seven Northeastern Cities Study. Obesity (Silver Spring). 2014;22(3):795-800.

8. Rundle A, Hoepner L, Hassoun A, et al. Association of childhood obesity with maternal exposure to ambient air polycyclic aromatic hydrocarbons during pregnancy. Am J

Epidemiol. Jun 1 2012;175(11):1163-1172.

9. Jerrett M, McConnell R, Wolch J, et al. Traffic-related air pollution and obesity formation in children: a longitudinal, multilevel analysis. Environ Health. 2014;13:49.

10. Kelishadi R, Mirghaffari N, Poursafa P, Gidding SS. Lifestyle and environmental factors associated with inflammation, oxidative stress and insulin resistance in children. Atherosclerosis. Mar 2009;203(1):311-319.

11. Thiering E, Cyrys J, Kratzsch J, et al. Long-term exposure to traffic-related air pollution and insulin resistance in children: results from the GINIplus and LISAplus birth cohorts. Diabetologia. Aug 2013;56(8):1696-1704.

12. Poursafa P, Mansourian M, Motlagh ME, Ardalan G, Kelishadi R. Is air quality index associated with cardiometabolic risk factors in adolescents? The CASPIAN-III Study. Environ Res. Oct 2014;134:105-109.

13. Janghorbani M, Momeni F, Mansourian M. Systematic review and metaanalysis of air pollution exposure and risk of diabetes. Eur J Epidemiol. Apr 2014;29(4):231-242.

14. Fleisch AF, Rifas-Shiman SL, Koutrakis $P$, et al. Prenatal exposure to traffic pollution: associations with reduced fetal growth and rapid infant weight gain. Epidemiology. Jan 2015;26(1):43-50. 
15. Oken E, Baccarelli AA, Gold DR, et al. Cohort profile: project viva. Int J Epidemiol. Feb 2015;44(1):37-48.

16. Gryparis A, Coull B, Schwartz J, Suh H. Semiparametric latent variable regression models for spatio-teomporal modeling of mobile source particles in the greater Boston area Journal of the Royal Statistical Society: Series C (Applied Statistics) 2007;56(2):183-209.

17. Kloog I, Melly SJ, Ridgway WL, Coull BA, Schwartz J. Using new satellite based exposure methods to study the association between pregnancy $\operatorname{PM}(2)$.(5) exposure, premature birth and birth weight in Massachusetts. Environ Health. 2012;11:40.

18. = Kloog I, Chudnovsky A, Just A, et al. A new hybrid spatio-temporal model for estimating daily multi-year PM2.5 concentrations across northeastern USA using high resolution aerosol optical depth data. Atmospheric Environment. 2014;95:581-590.

19. Perng W, Gillman MW, Mantzoros CS, Oken E. A prospective study of maternal prenatal weight and offspring cardiometabolic health in midchildhood. Ann Epidemiol. Nov 2014;24(11):793-800 e791.

20. Fleisch AF, Gold DR, Rifas-Shiman SL, et al. Air pollution exposure and abnormal glucose tolerance during pregnancy: the project Viva cohort. Environ Health Perspect. Apr 2014;122(4):378-383.

21. Oken E, Kleinman KP, Rich-Edwards J, Gillman MW. A nearly continuous measure of birth weight for gestational age using a United States national reference. BMC Pediatr. Jul 8 2003;3:6.

22. Karner AA, Eisinger DS, Niemeier DA. Near-roadway air quality: synthesizing the findings from real-world data. Environ Sci Technol. Jul 15 2010;44(14):5334-5344.

23. Environmental Protection Agency. Observational Data for Black Carbon. Available at: http://www.epa.gov/blackcarbon/2012report/Chapter5.pdf. Accessed 4 March 2015. 2012. Published Last Modified Date|. Accessed Dated Accessed|.

24. Mavanji V, Teske JA, Billington CJ, Kotz CM. Partial sleep deprivation by environmental noise increases food intake and body weight in obesity-resistant rats. Obesity (Silver Spring). Jul 2013;21(7):1396-1405.

25. Obayashi K, Saeki K, Iwamoto J, et al. Exposure to light at night, nocturnal urinary melatonin excretion, and obesity/dyslipidemia in the elderly: a cross-sectional analysis of the HEIJO-KYO study. J Clin Endocrinol Metab. Jan 2013;98(1):337-344.

26. Saelens BE, Sallis JF, Black JB, Chen D. Neighborhood-based differences in physical activity: an environment scale evaluation. Am J Public Health. Sep 2003;93(9):15521558.

27. Sioutas C, Delfino RJ, Singh M. Exposure assessment for atmospheric ultrafine particles (UFPs) and implications in epidemiologic research. Environ Health Perspect. Aug 2005;113(8):947-955.

28. Puett RC, Hart JE, Schwartz J, Hu FB, Liese AD, Laden F. Are particulate matter exposures associated with risk of type 2 diabetes? Environ Health Perspect. Mar 2011;119(3):384-389. 
29. Harris MH, Gold DR, Rifas-Shiman SL, et al. Prenatal and Childhood Traffic-Related Pollution Exposure and Childhood Cognition in the Project Viva Cohort (Massachusetts, USA). Environ Health Perspect. Oct 2015;123(10):1072-1078.

30. Bolton JL, Smith SH, Huff NC, et al. Prenatal air pollution exposure induces neuroinflammation and predisposes offspring to weight gain in adulthood in a sexspecific manner. FASEB J. Nov 2012;26(11):4743-4754.

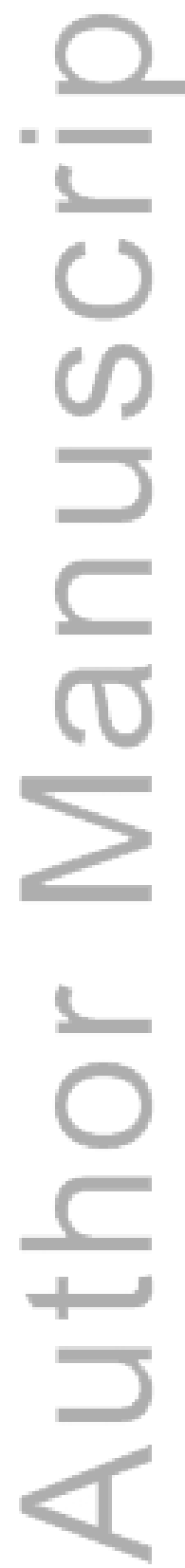


Table 1. Characteristics of study participants overall and by third trimester black carbon (BC) exposure

$3^{\text {rd }}$ trimester BC $\left(\mu \mathrm{g} / \mathrm{m}^{3}\right)$, Mean $(\mathrm{SD})$

\section{Maternal characteristics}

Age at enrollment (years)

Prepregnancy BMI $\left(\mathrm{kg} / \mathrm{m}^{2}\right)$

College graduate $(\%)$

Smoking habits $(\%)$

Never
Former
During pregnancy

Glucose tolerance $(\%)$

Normal

Failed GCT, normal OGTT

IGT

GDM

\section{Neighborhood characteristics}

Median household income in census tract $(\$)^{\text {a }}$

\section{Child characteristics in infancy}

Gestational age (weeks)

Quartiles of third trimester BC

\begin{tabular}{cc}
\hline Total & Q1 (lowest) \\
$0.69(0.23)$ & $0.40(0.09)$ \\
\hline Mean (SD) or \% & \\
$32.1(5.2)$ & $33.0(4.3)$ \\
$24.8(5.3)$ & $24.6(5.2)$ \\
68 & 78 \\
& \\
69 & 67 \\
20 & 24 \\
11 & 10 \\
& \\
83 & 82 \\
9 & 11 \\
3 & 3 \\
5 & 5
\end{tabular}

Q2 $\quad$ Q3 $\quad$ Q4 (highest)

$0.60(0.05) \quad 0.76(0.05) \quad 1.00(0.14)$

Mean (SD) or \%

$32.7(5.1)$
$24.8(5.6)$
71
68
21
11
82
10
3
5

$31.5(5.6)$
$24.6(5.0)$
66

$31.2(5.8)$

$25.3(5.6)$

58

71

18

11

18

12

85

85

6

3

6

7

4

4

\section{$57,763(21,656)$}

$70,993(20,006)$

$60,396(20,411)$

$53,505(20,740)$

$45,508(17,035)$

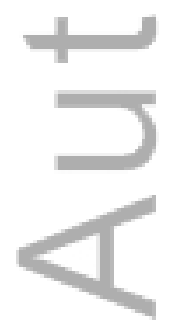
$39.5(1.7)$
$39.4(1.8)$
$39.6(1.6)$
$39.5(1.8)$
$39.5(1.8)$

(1)

(1.6)

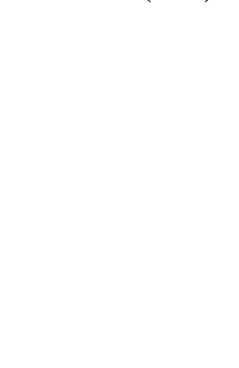

This article is protected by copyright. All rights reserved. 
Birth weight-for-gestational age z-score

Sex $(\%)$

Race/ethnicity $(\%)^{\mathrm{b}}$

White

Black

Hispanic

Asian

Other

Early childhood characteristics

Age at early childhood visit

BMI z-score

Waist circumference $(\mathrm{cm})$

Sum of skinfolds (mm)

Leptin (ng/mL)

Adiponectin $(\mu \mathrm{g} / \mathrm{mL})$

Mid-childhood characteristics

Age at mid-childhood visit

BMI z-score

Total fat mass $(\mathrm{kg})$

Truncal fat mass $(\mathrm{kg})$

Leptin (ng/mL)

Adiponectin $(\mu \mathrm{g} / \mathrm{mL})$

$0.20(0.97)$
49
64
17
6
5
9

$3.3(0.4)$

$0.5(1.0)$

$51.4(3.7)$

$16.7(4.3)$

$2.0(2.0)$

$22.3(5.6)$

$$
\begin{gathered}
8.0(0.9) \\
0.4(1.0) \\
7.5(3.9) \\
2.5(1.7) \\
6.1(7.5) \\
15.6(8.8)
\end{gathered}
$$

$0.32(1.02)$
47
84
5
1
3
7

$3.3(0.3)$

0.4 (1.0)

$51.4(3.5)$

16.7 (4.2)

$1.9(2.1)$

$22.8(5.2)$

$$
\begin{gathered}
7.8(0.7) \\
0.4(1.0) \\
7.0(3.2) \\
2.3(1.4) \\
5.6(6.6) \\
15.8(8.9)
\end{gathered}
$$

$0.20(0.93)$
50

67
14
6
5
8

$0.19(0.96)$

49

0.06 (0.94)

49

56
24
5
6
9

47

25

11

4

13

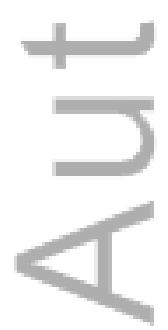

$3.3(0.3)$
$0.5(1.0)$
$51.4(3.5)$
$17.1(4.2)$
$1.8(1.7)$
$22.1(5.6)$

$3.3(0.4)$

0.4 (1.1)

$51.2(3.8)$

$16.6(4.7)$

$2.1(2.3)$

$22.4(5.4)$
$7.9(0.9)$
0.4 (1.0)
7.4 (3.9)
2.5 (1.8)
5.4 (6.5)
$14.4(8.8)$

$3.3(0.5)$
$0.5(1.0)$
$51.4(4.0)$
$16.5(4.2)$
$2.0(1.8)$
$22.0(5.9)$

$8.1(1.0)$

$0.5(1.0)$

$8.0(4.2)$

$2.7(1.8)$

$7.6(8.7)$

15.5 (8.9) 
HOMA-IR $1.9(1.8)$

$1.6(1.4)$

$1.8(1.4)$

$1.8(1.6)$

$2.3(2.5)$

Abbreviations: GCT: Glucose tolerance test; OGTT: Oral glucose tolerance test; IGT: Impaired glucose tolerance; GDM: Gestational diabetes mellitus

${ }^{\mathrm{a}}$ Based on address at the time of delivery

${ }^{b}$ Maternal race/ethnicity is substituted in $10 \%$ of children whose race/ethnicity is missing

This article is protected by copyright. All rights reserved. 
Table 2. Covariate-adjusted ${ }^{\mathrm{a}}$ associations of traffic-related air pollution in pregnancy and in early childhood with adiposity and cardiometabolic health in early childhood (median: 3.3 years of age). For black carbon, fine particulate matter, and traffic density exposures, estimates are mean difference (95\% confidence intervals) in outcome for each interquartile range increment in exposure. ${ }^{\mathrm{b}}$ For roadway proximity, estimates are mean difference (95\% confidence intervals) for each proximate category of roadway proximity versus $\geq 200 \mathrm{~m}$. Estimates with $95 \%$ confidence intervals that do not cross the null are bolded.

\begin{tabular}{|c|c|c|c|c|c|}
\hline 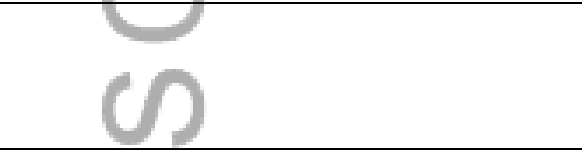 & $\begin{array}{l}\text { BMI z-score } \\
\quad \text { (z-units) }\end{array}$ & $\begin{array}{c}\text { Waist } \\
\text { circumference } \\
(\mathbf{c m})\end{array}$ & $\begin{array}{c}\text { Sum of skinfold } \\
\text { thickness } \\
(\mathrm{mm})\end{array}$ & $\begin{array}{c}\text { Leptin } \\
\text { (\% change) }\end{array}$ & $\begin{array}{l}\text { Adiponectin } \\
\text { (\% change) }\end{array}$ \\
\hline \multicolumn{6}{|l|}{$\begin{array}{l}\text { Black carbon (BC) exposure } \\
\left(\mu \mathrm{g} / \mathrm{m}^{3}\right)\end{array}$} \\
\hline Third trimester & $-0.0(-0.1,0.1)$ & $0.0(-0.3,0.4)$ & $-0.0(-0.4,0.4)$ & $7.4(-1.7,17.3)$ & $-2.1(-6.2,2.3)$ \\
\hline Year prior to early childhood visit & $-0.0(-0.1,0.1)$ & $-0.1(-0.4,0.3)$ & $-0.1(-0.4,0.3)$ & $3.0(-4.9,11.6)$ & $-0.6(-4.5,3.4)$ \\
\hline \multicolumn{6}{|l|}{$\begin{array}{l}\text { Fine particulate }\left(\mathrm{PM}_{2.5}\right) \text { exposure } \\
\left(\mu \mathrm{g} / \mathrm{m}^{3}\right)\end{array}$} \\
\hline Third trimester & $0.0(-0.1,0.1)$ & $0.2(-0.1,0.5)$ & $0.3(-0.1,0.6)$ & $-5.4(-12.4,2.1)$ & $-3.1(-6.7,0.6)$ \\
\hline Year prior to early childhood visit & $-0.0(-0.1,0.1)$ & $-0.2(-0.6,0.2)$ & $0.3(-0.2,0.8)$ & $8.8(-1.4,20.0)$ & $-0.9(-5.6,4.0)$ \\
\hline \multicolumn{6}{|l|}{ Near-residence traffic density } \\
\hline Birth address & $0.0(-0.0,0.1)$ & $0.0(-0.1,0.2)$ & $0.0(-0.2,0.2)$ & $5.4(1.3,9.7)$ & $0.0(-1.9,2.0)$ \\
\hline Early childhood address & $0.0(-0.0,0.1)$ & $-0.0(-0.2,0.1)$ & $0.0(-0.2,0.2)$ & $2.0(-1.5,5.6)$ & $0.8(-0.9,2.5)$ \\
\hline \multicolumn{6}{|l|}{$\begin{array}{l}\text { Proximity to major roadway, birth } \\
\text { address }\end{array}$} \\
\hline$<50 \mathrm{~m}$ & $0.3(0.0,0.7)$ & $1.7(0.6,2.8)$ & $1.9(0.6,3.2)$ & $40.7(5.2,88.1)$ & $1.1(-12.3,16.5)$ \\
\hline$-<100 \mathrm{~m}$ & $-0.0(-0.4,0.3)$ & $0.0(-1.2,1.3)$ & $0.1(-1.3,1.5)$ & $21.0(-8.6,60.2)$ & $-2.0(-14.6,12.4)$ \\
\hline $100-<200 \mathrm{~m}$ & $0.4(0.1,0.6)$ & $1.0(0.1,1.8)$ & $0.7(-0.3,1.7)$ & $17.4(-7.7,49.2)$ & $-13.1(-22.7,-2.3)$ \\
\hline$\geq 200 \mathrm{~m}$ & Reference & Reference & Reference & Reference & Reference \\
\hline
\end{tabular}

Proximity to major roadway, early

childhood address

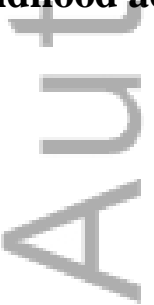




\begin{tabular}{|c|c|c|c|c|c|}
\hline$<50 \mathrm{~m}$ & $0.1(-0.2,0.5)$ & $0.8(-0.5,2.1)$ & $1.1(-0.4,2.7)$ & $41.7(3.0,94.9)$ & $9.5(-6.3,28.0)$ \\
\hline $50 \quad 100 \mathrm{~m}$ & $-0.0(-0.4,0.3)$ & $-0.1(-1.4,1.2)$ & $-0.8(-2.3,0.6)$ & $-8.0(-33.2,26.6)$ & $-9.5(-22.5,5.8)$ \\
\hline $100-<200 \mathrm{~m}$ & $0.1(-0.2,0.3)$ & $-0.1(-1.0,0.7)$ & $0.1(-0.9,1.1)$ & $0.4(-19.0,24.5)$ & $2.0(-8.2,13.3)$ \\
\hline$\geq 200 \mathrm{~m}$ & Reference & Reference & Reference & Reference & Reference \\
\hline
\end{tabular}

${ }^{a}$ Model adjusted for characteristics of child (age, sex, race/ethnicity), mother (age, education, smoking during pregnancy), and neighborhood (census tract median income), as well as season and date of health outcome.

${ }^{\mathrm{b}}$ Interquartile range $=0.33 \mu \mathrm{g} / \mathrm{m}^{3}$ for third trimester BC, $0.22 \mu \mathrm{g} / \mathrm{m}^{3}$ for BC during the year prior to the early childhood visit, 2.20 $\mu \mathrm{g} / \mathrm{m}^{3}$ for third trimester $\mathrm{PM}_{2.5}, 1.33 \mu \mathrm{g} / \mathrm{m}^{3}$ for $\mathrm{PM}_{2.5}$ during the year prior to the early childhood visit, $1,454 \mathrm{~km} * \mathrm{vehicles} / \mathrm{day}$ for traffic density at birth, and 1,247 km*vehicles/day for traffic density at early childhood address.

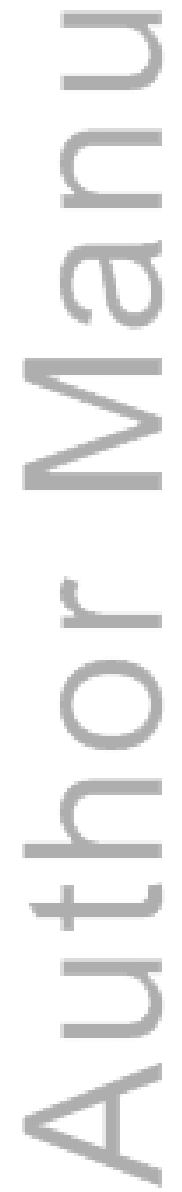


Table 3. Covariate-adjusted ${ }^{\mathrm{a}}$ associations of traffic-related air pollution in pregnancy and in mid-childhood with adiposity and cardiometabolic health in mid-childhood (median: 7.7 years of age). For black carbon, fine particulate matter, and traffic density exposures, estimates are mean difference (95\% confidence intervals) in outcome for each interquartile range increment in exposure. ${ }^{\mathrm{b}}$ For roadway proximity, estimates are mean difference (95\% confidence intervals) for each proximate category of roadway proximity versus $\geq 200 \mathrm{~m}$. Estimates with $95 \%$ confidence intervals that do not cross the null are bolded.

\begin{tabular}{|c|c|c|c|c|c|c|}
\hline & $\begin{array}{l}\text { BMI z-score } \\
\quad \text { (z-units) }\end{array}$ & $\begin{array}{l}\text { Total fat mass } \\
\qquad(\mathbf{k g})\end{array}$ & $\begin{array}{c}\text { Truncal fat } \\
\text { mass } \\
(\mathrm{kg})\end{array}$ & $\begin{array}{c}\text { Leptin } \\
\text { (\% change) }\end{array}$ & $\begin{array}{l}\text { Adiponectin } \\
\text { (\% change) }\end{array}$ & $\begin{array}{l}\text { HOMA-IR } \\
\text { (\% change) }\end{array}$ \\
\hline \multicolumn{7}{|l|}{$\begin{array}{l}\text { Black carbon (BC) exposure } \\
\left(\mu \mathrm{g} / \mathrm{m}^{3}\right)\end{array}$} \\
\hline Third trimester & $-0.0(-0.1,0.1)$ & $-0.2(-0.5,0.2)$ & $-0.1(-0.2,0.1)$ & $4.0(-6.6,15.7)$ & $2.4(-4.9,10.3)$ & $1.1(-8.8,12.1)$ \\
\hline Year prior to mid-childhood visit & $-0.1(-0.2,0.0)$ & $0.0(-0.3,0.4)$ & $0.0(-0.1,0.2)$ & $3.5(-6.8,15.0)$ & $1.3(-5.9,9.0)$ & $3.9(-5.9,14.6)$ \\
\hline \multicolumn{7}{|l|}{$\begin{array}{l}\text { Fine particulate }\left(\mathrm{PM}_{2.5}\right) \\
\text { exposure }\left(\mu \mathrm{g} / \mathrm{m}^{3}\right)\end{array}$} \\
\hline Third trimester & $-0.0(-0.1,0.0)$ & $-0.2(-0.6,0.1)$ & $-0.1(-0.2,0.1)$ & $-5.1(-14.7,5.6)$ & $-5.0(-11.7,2.3)$ & $2.8(-6.6,13.0)$ \\
\hline Year prior to mid-childhood visit & $-0.2(-0.4,-0.1)$ & $-0.6(-1.2,-0.1)$ & $-0.3(-0.5,-0.0)$ & $-12.1(-24.9,2.8)$ & $-2.8(-13.0,8.6)$ & $-17.8(-29.2,-4.7)$ \\
\hline \multicolumn{7}{|l|}{ Near-residence traffic density } \\
\hline Birth address & $0.0(-0.0,0.1)$ & $0.0(-0.2,0.2)$ & $-0.0(-0.1,0.1)$ & $4.0(-1.3,9.6)$ & $0.6(-3.0,4.3)$ & $-5.7(-10.1,-1.1)$ \\
\hline Mid-childhood address & $-0.0(-0.1,0.0)$ & $0.0(-0.1,0.2)$ & $0.0(-0.1,0.1)$ & $1.9(-2.6,6.6)$ & $-0.9(-4.1,2.3)$ & $0.1(-4.2,4.5)$ \\
\hline \multicolumn{7}{|l|}{$\begin{array}{l}\text { Proximity to major roadway, } \\
\text { birth address }\end{array}$} \\
\hline$<50 \mathrm{~m}$ & $0.1(-0.2,0.5)$ & $2.1(0.8,3.5)$ & $0.9(0.4,1.5)$ & $78.3(18.5,168.3)$ & $-13.2(-34.7,15.4)$ & $-0.2(-33.6,49.8)$ \\
\hline 50 & $-0.0(-0.4,0.4)$ & $-0.5(-2.0,1.0)$ & $-0.3(-0.9,0.4)$ & $-4.9(-36.0,41.3)$ & $-1.2(-25.0,30.2)$ & $-32.4(-53.6,-1.4)$ \\
\hline $100-<200 \mathrm{~m}$ & $0.3(0.0,0.5)$ & $1.1(0.1,2.0)$ & $0.4(-0.0,0.8)$ & $1.2(-21.5,30.5)$ & $1.0(-15.4,20.5)$ & $-6.3(-27.2,20.7)$ \\
\hline$\geq 200 \mathrm{~m}$ & Reference & Reference & Reference & Reference & Reference & Reference \\
\hline
\end{tabular}

Proximity to major roadway,

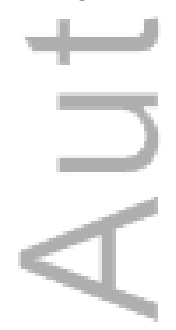




\begin{tabular}{|c|c|c|c|c|c|c|}
\hline \multicolumn{7}{|l|}{ mid-childhood address } \\
\hline$<50 \mathrm{~m}$ & $-0.0(-0.4,0.4)$ & $0.1(-1.4,1.6)$ & $0.0(-0.6,0.7)$ & $46.6(-5.3,127.1)$ & $-13.5(-36.1,17.2)$ & $-1.8(-36.6,52.3)$ \\
\hline $50-<100 m$ & $-0.1(-0.5,0.3)$ & $-1.0(-2.5,0.5)$ & $-0.4(-1.1,0.2)$ & $-19.1(-45.5,20.0)$ & $0.4(-23.6,32.0)$ & $-13.1(-41.3,28.6)$ \\
\hline $100-<200 \mathrm{~m}==$ & $0.1(-0.2,0.3)$ & $0.4(-0.6,1.5)$ & $0.2(-0.3,0.6)$ & $8.6(-18.0,43.9)$ & $5.6(-13.1,28.3)$ & $-5.8(-29.4,25.8)$ \\
\hline$\geq 200 \mathrm{~m}$ & Reference & Reference & Reference & Reference & Reference & Reference \\
\hline
\end{tabular}

${ }^{a}$ Model adjusted for characteristics of child (age, sex, race/ethnicity), mother (age, education, smoking during pregnancy), neighborhood (census tract median income), as well as season and date of health outcome.

${ }^{\mathrm{b}}$ Interquartile range $=0.33 \mu \mathrm{g} / \mathrm{m}^{3}$ for third trimester $\mathrm{BC}, 0.20 \mu \mathrm{g} / \mathrm{m}^{3}$ for BC during the year prior to the mid-childhood visit, 2.20 $\mu \mathrm{g} / \mathrm{m}^{3}$ for third trimester $\mathrm{PM}_{2.5}, 1.66 \mu \mathrm{g} / \mathrm{m}^{3}$ for $\mathrm{PM}_{2.5}$ during the year prior to the mid-childhood visit, 1,454 km*vehicles/day for traffic density at birth, and $1,186 \mathrm{~km} *$ vehicles/day for mid-childhood traffic density. 